\title{
Testicular Sertoli Cell Tumor, Lipid Rich Variant
}

National Cancer Institute

\section{Source}

National Cancer Institute. Testicular Sertoli Cell T umor, Lipid Rich Variant. NCI Thesaurus.

Code C39943.

A testicular Sertoli cell tumor in which the neoplastic cells have clear and vacuolated cytoplasm due to accumulation of intracytoplasmic lipids. 